\title{
Balanced Intelligent Process Control Systems
}

\author{
R. Sanz, A. Jiménez, R. Galán and F. Matia \\ Intelligent Control Group \\ Departamento de Automática, Electrónica e Informática Industrial \\ UNIVERSIDAD POLITÉCNICA DE MADRID \\ José Gutierrez Abascal 2, 28006 Madrid, SPAIN \\ Tel: +34 (]) 3363061, Fax: +34(1)5642961 \\ e-Mail:sanz@disam.upm.es
}

\begin{abstract}
Intelligent process control systems are intrinsically balanced automation systems. Lack of knowledge about process behavior appears in model prediction deviations from plant real behavior. This makes impossible achieving full autonomy of process plants even with the best controllers. Artificial intelligence provides mechanisms for incorporating human knowledge in the process control system. But the levels of autonomy that can be reached are far from those obtained in manufacturing applications. This lead to truly man-machine control systems in which exist a balance not only at design stages but in real time operation. Our group has been building this kind of systems and environments following the idea of man-machine layered intelligent control. Some developments in this area are presented in this paper.
\end{abstract}

Keywords

Layered control, intelligent process control, software architectures, user interfaces, software engineering environments.

\section{INTRODUCTION}

In complex continuous process plants there has been a traditional gap between control requirements and control capabilities of control systems. Conventional controllers were unable to cope with all the problems that lead to bad operation of the plant. Dependability and safety were the main criteria that led to the use of humans to perform control tasks in these systems.

The introduction of artificial intelligence (Boullart, 92) was seen as a major step towards plant autonomy, because of the potential capability of emulating high level human behavior. Expert systems were the tools mostly used to put 'intelligence' in process controllers. 
Enlightenment about the relation between our work and balanced automation systems came from the introduction to the collection of papers from BASYS'95. As Camarinha-Matos and Afsarmanesh pointed there "Balanced automation captures the idea of an appropriate level of technical automation, as opposed to both the pure anthropocentric or the total automation" (Camarinha-Matos, 95). This is really what are we trying to achieve when putting artificial intelligence technologies in plant control systems.

Ten years ago we were starting our research in intelligent process control systems. Those days, experiences of using artificial intelligence in continuous process automation were limited to some small first generation expert systems (David, 93) or fuzzy controllers (Matía, 94). But the role of men in automation systems was indeed an open question. In 1983 Pergamon Press published a special number of Automatica entitled "Control Frontiers in Knowledge Based and Man Machine Systems". The paper of Sheridan (Sheridan, 83) presented an order of "degrees of assistance" that computers can provide for automation. These degrees are shown in the following figure.

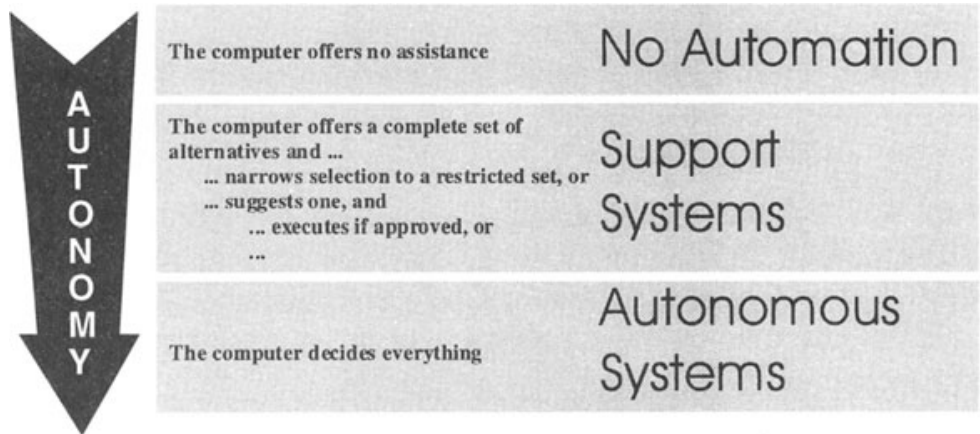

Figure 1: A view on Sheridan's degrees of Automation.

Even when it seems obvious, many people building intelligent process controllers are not aware of the need of integrating human into the control loop.

\section{LAYERED INTELLIGENT CONTROL}

The approach to intelligent control in our group is layered intelligent control. This idea is quite simple: if you want to put some new behavior on a system put a control system on it. It does not matter if the system has another controller yet; you can add functionality -obviously with limitations- by adding new control loops over existent control loops.

This approach offers several advantages, with three of special importance: Smooth migration to new control technology; reliability of final nested controllers and full spectrum of speed/intelligence. 
This approach to intelligent control offers good ways to balance control responsibilities between humans and computers. But there still exist a need for better man-machine interfaces to achieve full embedding of humans in control systems.

The approach of layered control led to a decomposition of control levels -see Figure 3 laterthat can be freely assigned to control agents, even intelligent ones. Higher control levels can be broadly grouped in reactive control (also called operational), tactical control and strategical control.

These levels are provided in several systems developed by our group. The evolution of the systems is due to a bias towards a specific life cycle for intelligent controllers, in which plant operators get involved in early stages of development.

\section{THE CONEX SYSTEM}

The CONEX system was an ad-hoc development for intelligent control of a cement kiln. It was a distributed multiagent system in which control functions were assigned using a speed vs. intelligence criteria (Sanz, 90).

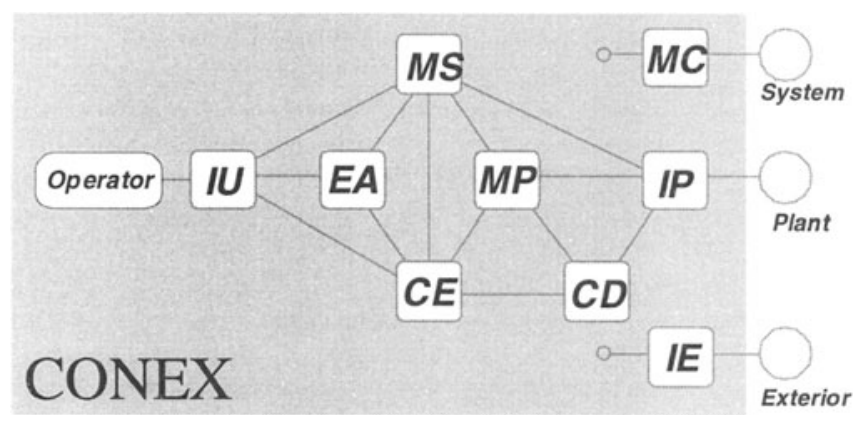

Figure 2: CONEX agent interactions.

The agents in CONEX were Process interface (IP), Direct control (CD), Pattern based control (MP), Expert control (CE), Model based control (EA), Model and simulator (MS), Operator interface (IU), CONEX monitor (MC) and an External interface (IE). 
The relevance of this architecture from the point of view of balanced systems comes from the idea that operators are yet another controllers, with highest intelligence and lowest speed. This in fact is not true in all cases, because humans can perform faster and better than automated systems in some cases, specially those most dangerous.

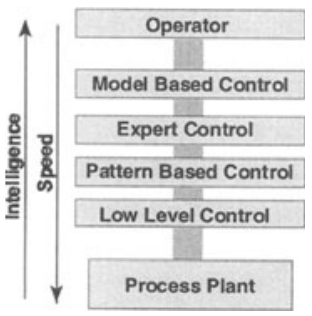

\section{THE HINT SYSTEM}

Figure 3: CONEX Layers

The activities in CONEX gave rise to our participation in the HINT project (Heterogeneous INTegration architecture for intelligent control systems) (Alarcón, 94). HINT was an Esprit project (\#6447), partially funded by the Commission of the European Communities, which has produced a coherent framework for integrating different techniques, mostly AI ones, in order to overcome the obstacles mentioned in the above paragraphs and to provide solutions to process control problems which require the kind of intelligent supervision that is presently carried out by human operators.

The main results of the project can be summarized in a methodology, an architecture and some problem-solving software components. The components developed were based on artificial intelligence technologies and were situated in the full spectrum of automation layers. A big effort was put in the integration of human operators in the control system. An expert system based DSS (decision support system) was the main component of the demonstration application.

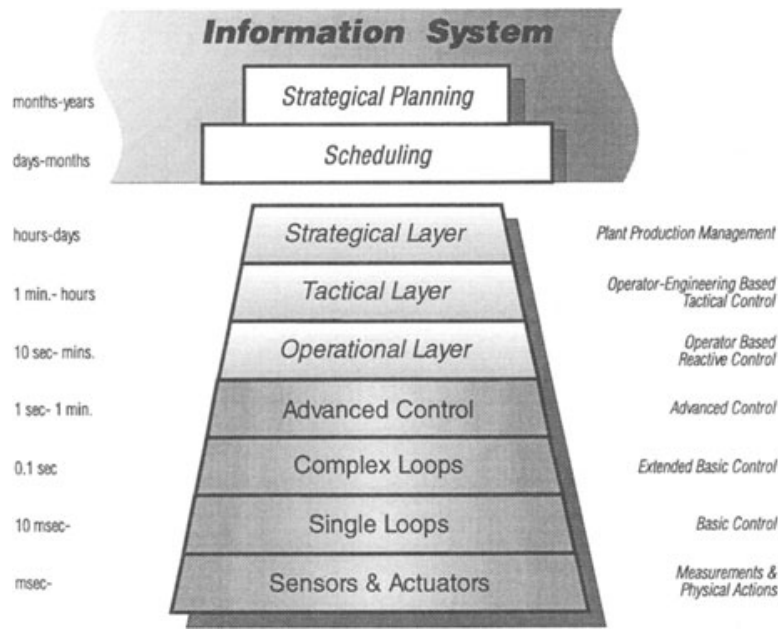

Figure 4: Control layers in a HINT system. 
The development of an integration methodology was the main point in HINT. This development was aimed at facilitating and guaranteeing the coherent interaction between multiple heterogeneous techniques in the task of solving industrial control problems. This integration methodology (i) defines when specific control problems are suitable to be solved by the cooperation of the different techniques. (ii) Specifies the different phases to follow when integrating different AI based technologies, namely the definition, analysis, knowledge acquisition, conceptualization and design phase. (iii) Defines the vehicles means by which this integration can be carried out.

The architecture was a fairly simple monohost blackboard (Engelmore, 88). In it a centralized and active data structure (the blackboard) is the only means of communication among problem solving modules. It is also the vehicle for cooperative problem solving and it is responsible for data coherence within the whole system.

It is very important to note that, as part of the HINT project, a demonstrator has been implemented and installed in a petrochemical plant owned by Repsol S.A (one of the major Spanish firms and a member of the HINT consortium) in Cartagena, Spain, in order to make sure of the suitability of the approach. This demonstrator is currently being used by the control team of the plant and it is already showing very promising results.

Several AI based modules have been developed in this demonstrator as an example of the various techniques that can be used in a HINT-like application. In this particular case, balancing is not the issue because the system does no perform control tasks, but the whole development -architecture, methodology and components- is oriented towards integrated manmachine systems.

The HINT methodology provides a good way to achieve proper balancing between man and machine: the maquette approach to development. It is a type of rapid prototypying, but what provides the prototype is mostly look and feel and some little functionality. The maquette is developed in parallel with the real final system -with reduced effort providing early feedback to get a better integration with plant operators.

\section{THE MITA SYSTEM}

The present research of the Intelligent Control Group is centered in a new system called MITA. MITA stands for Integration Methodology and Advanced Technologies for Intelligent Control Systems. The focus of this research is threefold:

- The development of a Methodology derived from HINT Methodology. One of the main points in the methodology is that it provides a metaarchitecture (Bhansali, 94).

- The development of a Software Engineering Environment (SEE) called ICE (Intelligent Control Environment). 
- The enhancement of available core intelligent control technologies and the incorporation of new ones: neurocontrol, fuzzy control, learning control, etc.

In the writing of Camarinha-Matos and Afsarmanesh mentioned in the introduction, they pointed out what areas need further research in the topics of BASYS. This areas are presented in the following table showing how our research in MITA is related with them.

\begin{tabular}{|l|l|}
\hline Area & MITA point of view \\
\hline Modeling and analysis & $\begin{array}{l}\text { The core component of MITA is an heterogeneous } \\
\text { modeling technology. }\end{array}$ \\
\hline Teamwork infrastructure design & $\begin{array}{l}\text { The SEE under development, will provide a CSCW } \\
\text { environment for engineering intelligent control systems. }\end{array}$ \\
\hline Decision support tools & $\begin{array}{l}\text { Decision support systems based on expert system } \\
\text { technology are part of the SEE and are also core } \\
\text { components for control systems. }\end{array}$ \\
\hline Rapid model prototyping & $\begin{array}{l}\text { The modeling environment of the SEE will provide } \\
\text { tools for early design and implementation validation } \\
\text { based on rapid prototyping concepts from the } \\
\text { methodology. }\end{array}$ \\
\hline Migration methodologies & $\begin{array}{l}\text { As mentioned earlier, layered intelligent control offers } \\
\text { good migration paths to new control technology. }\end{array}$ \\
\hline
\end{tabular}

The objective of MITA will be dual, providing an extension of capabilities and tools for better and easier use of CONEX and HINT technologies.

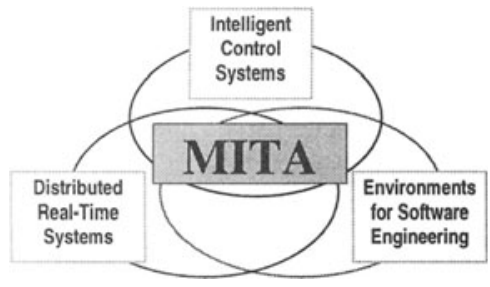

Figure 5: MITA relations.

The expected developments in MITA will be interdisciplinary, being situated in the intersection of: (i) intelligent control systems, (ii) distributed realtime systems, and (iii) environments for software engineering.

We can summarize -and name this area- as Computer Aided Intelligent Control System Engineering.

In our research a main objective is building tools (De Grace, 92) to build the right control systems. The systems that plant personnel need. The final product of MITA will be a DODE (Domain Oriented Design Environment) for layered intelligent control.

\section{CONCLUSIONS}

Our final conclusion is that human experience is the best asset is complex process control. So work must be done in coping with problems of humans involved in control systems. 
Cognitive overload, fact significance, change detection, even eye strain can produce losses in plant operation.

Control systems must be smarter but they must be also cooperative and informative with humans that operate them. The maquette approach used in HINT is a good way to increasing plant personnel involvement in control systems design.

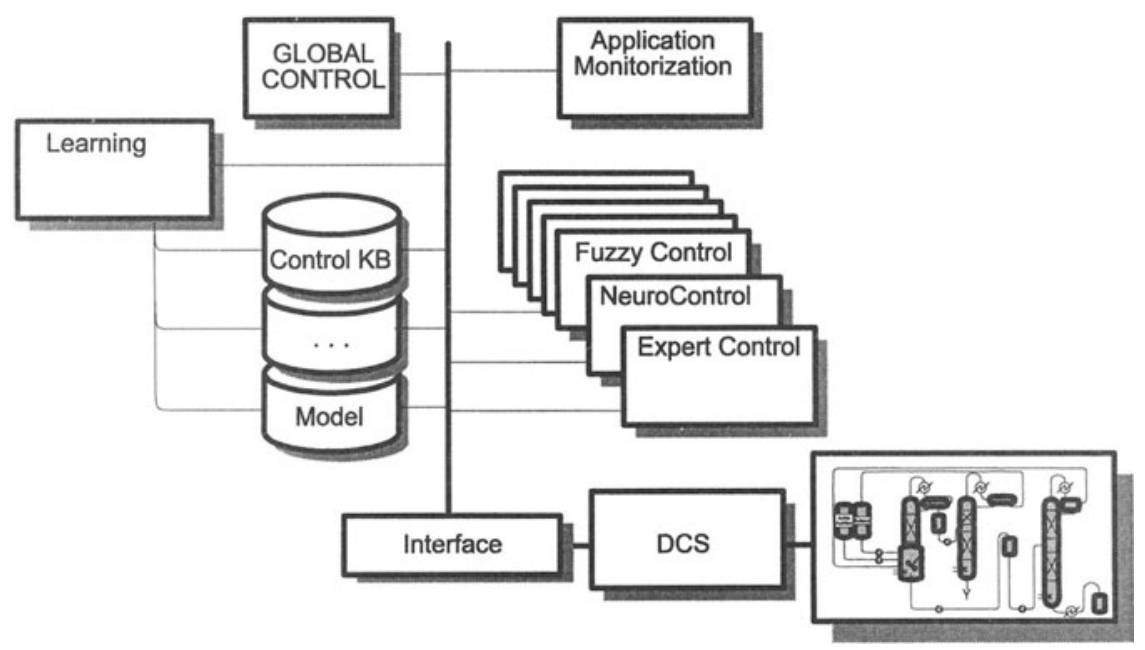

Figure 6: Example MITA application for chemical plant control.

From the inner point of view, intelligent control systems design must begin with a careful operator task analysis and correct balance of responsibility. At the end humans are responsible of the correct operation of the whole system, so they must be confident with the automated activities of the control system. Success of advanced technologies in process control should not be measured by the economy gains or the reliability enhancements but by their operation time. The time that operators let them do their work.

\section{AKNOWLEDGMENTS}

We would like to acknowledge the support from ASLAND S.A., CICYT and CEU through projects HINT and CIMIS.net.

\section{REFERENCES}

Alarcón, M. I. et. al.. An Integration Methodology and Architecture for Intelligent Systems in Process Control: The HINT Project. IFAC Workshop on Artificial Intelligence in RealTime Control. 1994. 
Bhansali, S. Software Synthesis using Generic Architectures. Automated Software Engineering, Vol. 1 No. 3/4, pp. 239-279, 1994.

Boullart, L., Krijsman, A. and Vingerhoeds, R.A. (Eds) Application of Artificial Intelligence in Process Control. Pergamon, 1992.

Camarinha-Matos, L. M. and Afsarmanesh, H.. Balanced Automation Systems. Architectures and Design Methods. Chapman \& Hall. 1995.

David, J.M., Krivine, J.P. and Simmons, R. (Eds) Second Generation Expert Systems. Springer-Verlag, 1993.

De Grace, P. and Stahl, L.H. The Olduvai Imperative. Prentice-Hall, 1992.

Engelmore, R. and Morgan, T. (Eds) Blackboard Systems. Addison Wesley, 1988.

Fischer, G. Domain-Oriented Design Environments. Automated Software Engineering, Vol. 1 No. 2, pp. 177-203, 1994.

HINT Consortium. HINT Manual for System Developers. 1994.

Matía, F.. Diseño y Construcción de Sistemas de Control Borroso. Ph.D. Thesis. Universidad Politécnica de Madrid. 1994.

Rosemberg, D. and Hutchinson, C. (Eds). Design issues in CSCW. Springer-Verlag, 1994.

Sanz, R. Arquitectura de Control Inteligente de Procesos. PhD Thesis. Universidad Politécnica de Madrid. 1990.

Sheridan, T.B. Vámos T. and Aida S.. Adapting Automation to Man Culture and Society. Automática, Vol. 19 No. 6, pp 605-612, 1983.

\section{BIOGRAPHY}

Ricardo Sanz was born in Tomellosa de Tajuña, Spain, in 1963. He became Industrial Engineer at the Escuela Técnica Superior de Ingenieros Industriales of the Universidad Politécnica de Madrid, and got the PhD degree by the U.P.M. in 1990. Now he is associate professor in the area of Systems Engineering at the Departamento de Automática, Ingeniería Electrónica e Informática Industrial of the U.P.M. His main activities have been in the area of process control, artificial intelligence, software engineering and software architecture. Now he is involved in some $\mathrm{R}+\mathrm{D}$ projects in the area of intelligent and conventional process control. 